\title{
Comparison of baseline characteristics, treatment and clinical outcomes of critically ill COVID-19 patients admitted in the first and second waves in Australia
}

Aidan JC Burrell, Ary Serpa Neto, Tessa Broadley, Tony Trapani, Husna Begum, Lewis T Campbell, Allen C Cheng, Winston Cheung, D James Cooper, Simon J Erickson, Craig J French, John M Kaldor, Edward Litton, Srinivas Murthy, Richard E McAllister, Alistair D Nichol, Annamaria Palermo, Mark P Plummer, Mahesh Ramanan, Benjamin AJ Reddi, Claire Reynolds, Steve A Webb and Andrew A Udy, for the SPRINT SARI Australia Investigators*

In December 2019, several cases of atypical pneumonia caused by infection with severe acute respiratory syndrome coronavirus 2 (SARS-CoV-2) were reported in Wuhan, China. ${ }^{1-3}$ This novel pathogen has now become responsible for a global pandemic of coronavirus disease 2019 (COVID-19), affecting over 190 million people worldwide and causing over 4.1 million deaths. ${ }^{4}$

Although research concerning COVID-19 has been produced at an extraordinary rate, longitudinal data comparing changes in clinical practice or the translation of new evidence into bedside care have traditionally lagged behind. ${ }^{5,6}$ Indeed, there is currently limited evidence concerning what impact changes to public health measures (including travel bans, face masks, and social restrictions), the publication of several major trials (such as the RECOVERY7 and ACTT-18 trials), and changes in clinical practice ${ }^{9}$ have had on patient demographics, patient care, and outcomes.

Australia experienced a first wave of infections from February to June 2020.10 In late June 2020, an outbreak likely originating from a quarantine facility in Melbourne resulted in a second wave of COVID-19 cases predominantly in the state of Victoria, resulting in the re-establishment of public health interventions to control the spread of SARSCoV-2. The start of this second wave was also close to the publication of the two aforementioned large, multicentre, randomised controlled trials (RCTs) concerning specific COVID-19 therapies.

In this context, the aim of this study was to report the longitudinal differences in baseline characteristics, treatment and outcomes in patients with COVID-19 admitted to intensive care units (ICUs) between the first and second waves in Australia.

\section{Methods}

\section{Study design}

This was a multicentre, inception cohort study involving ICUs in Australia. Ethics approval was granted for each participating site via the Alfred Hospital (HREC/16/

\begin{abstract}
Objective: To report longitudinal differences in baseline characteristics, treatment, and outcomes in patients with coronavirus disease 2019 (COVID-19) admitted to intensive care units (ICUs) between the first and second waves of COVID-19 in Australia.
\end{abstract}

Design, setting and participants: SPRINT-SARI Australia is a multicentre, inception cohort study enrolling adult patients with COVID-19 admitted to participating ICUs. The first wave of COVID-19 was from 27 February to 30 June 2020, and the second wave was from 1 July to 22 October 2020. Results: A total of 461 patients were recruited in 53 ICUs across Australia; a higher number were admitted to the ICU during the second wave compared with the first: 255 (55.3\%) versus $206(44.7 \%)$. Patients admitted to the ICU in the second wave were younger ( $58.0 \vee 64.0$ years; $P=0.001$ ) and less commonly male (68.9\% $\vee 60.0 \% ; P=0.045)$, although Acute Physiology and Chronic Health Evaluation (APACHE) II scores were similar (14 $v 14 ; P=0.998)$. High flow oxygen use $(75.2 \% \vee 43.4 \% ; P<0.001)$ and noninvasive ventilation $(16.5 \% \vee 7.1 \% ; P=0.002)$ were more common in the second wave, as was steroid use $(95.0 \% \mathrm{~V}$ $30.3 \% ; P<0.001)$. ICU length of stay was shorter $(6.0 v 8.4$ days; $P=0.003)$. In-hospital mortality was similar $(12.2 \% \mathrm{~V}$ $14.6 \% ; P=0.452$ ), but observed mortality decreased over time and patients were more likely to be discharged alive earlier in their ICU admission (hazard ratio, $1.43 ; 95 \% \mathrm{Cl}$, 1.13-1.79; $P=0.002$ ).

Conclusion: During the second wave of COVID-19 in Australia, ICU length of stay and observed mortality decreased over time. Multiple factors were associated with this, including changes in clinical management, the adoption of new evidence-based treatments, and changes in patient demographic characteristics but not illness severity.

Crit Care Resusc 2021; 23 (3): 308-19 


\section{ORIGINAL ARTICLE}

Alfred/59) or by separate applications to individual sites. The requirement for written informed consent from individual patients was waived.

\section{Setting}

Participating sites across Australia were identified following an expression of interest to the Australian and New Zealand Intensive Care Society Clinical Trials Group (ANZICS CTG) or through previous affiliation with the Short PeRiod IncideNce sTudy of Severe Acute Respiratory Infection (SPRINT-SARI) Australia project. Data were retrieved from 53 ICUs in Australia enrolling adult patients into SPRINT-SARI Australia. Originally, SPRINT-SARI was prepared to capture data in 78 ICUs over all Australia. However, due to the limited nature of the Australian outbreak, most of these ICUs did not receive patients with COVID-19.

\section{Participants}

All patients admitted to the ICU were included if they were older than 16 years and were polymerase chain reaction (PCR)-positive for COVID-19. Data of patients transferred between ICUs were aggregated and counted as a single ICU admission. This cohort captured more than $99 \%$ of all ICU admissions due to COVID-19 in Australia. ${ }^{11}$ In addition, the data used for the COVID-19 period were also utilised by the Australian Government Department of Health to produce official fortnightly reports about patients with COVID-19 in the ICU. A description and road map of restrictions in Australia during COVID-19 are shown in the Online Appendix.

\section{Data collection}

The case report form used for data collection had extensive development by local and international clinical experts and included standardised data fields that aligned with SPRINTSARI International. ${ }^{12}$ Data in this report were entered by research coordinators at participating sites. The patient's relevant background and presenting symptoms were recorded on the day of study recruitment. Daily follow-up was then completed until discharge from ICU. A final form was completed with details of the hospital outcomes.

To support rapid data collection and reporting, SPRINTSARI Australia hosts a data platform that includes an electronic data capture system, a secure repository and an analytic framework. Data were entered into a web-based REDCap data management system, securely stored, and used to inform regular reports. Further details about SPRINTSARI Australia have been described elsewhere. ${ }^{10}$

\section{Data definitions}

Patients were categorised as part of the first wave if their ICU admission date was between 27 February and 30 June 2020 and as part of the second wave for ICU admissions between 1 July 2020 and 22 October 2020. Age was categorised as $<60,60-69,70-79$ and $\geq 80$ years. Patients transferred between ICUs were counted as a single ICU admission. No assumptions were made regarding missing data (Online Appendix, eTable4); all proportions were calculated as percentages of the patients with available data.

\section{Clinical outcomes}

In addition to an overall description of different characteristics during the two waves, the following patientrelated outcomes were described in more detail:

- duration of ventilation in patients receiving invasive ventilation;

- ICU length of stay;

- hospital length of stay;

- ICU mortality; and

- in-hospital mortality.

The following outcomes reflecting process of care were assessed during any time in the patients' hospital admission:

- number of patients treated with mechanical ventilation;

- number of patients treated with high flow nasal cannula;

- number of patients treated with steroids;

- number of patients treated with remdesevir; and

- number of patients treated with prone positioning.

\section{Statistical analysis}

All data are reported according to the relevant time period (eg, first or second wave). Descriptive statistics for all variables were calculated. Continuous variables are reported as medians with interquartile ranges (IQRs) and categorical variables as percentages with $95 \%$ confidence intervals (Cls), where appropriate.

Univariable comparisons between periods (with the first wave as reference) were performed with generalised linear modelling with binomial distribution and identity link for categorical variables, and with quantile models considering a $T=0.50$ and an asymmetric Laplace distribution, for continuous variables. Differences in categorical variables are presented as risk difference with $95 \% \mathrm{Cl}$, and in continuous variables as median difference with $95 \% \mathrm{Cl}$. Categorical variables with more than two categories were compared using Fisher exact tests and no effect estimate is presented.

Time until ICU and hospital discharge is presented in cumulative incidence plots, with death before discharge treated as a competing risk. The groups were compared and subdistribution hazard ratios were estimated with a FineGray competing risk model. All models were reassessed in adjusted analysis considering Acute Physiology and Chronic Health Evaluation (APACHE) II score as a covariate and the centre as random effect. 


\section{ORIGINAL ARTICLE}

Change in mortality over time against severity of illness was assessed by generating an exponentially weighted moving average (EWMA) plot. The EWMA was constructed considering a weight of 0.005 , a target based on the initial predicted risk of death for each disease, and the boundaries of the predicted risk being three standard deviations. The predicted risk of death was derived from APACHE ॥ considering admission due to respiratory infection. In the EWMA plot, we compared the observed in-hospital mortality with APACHE II-predicted mortality to monitor changes in this variable over time. The EWMA is an approach used to monitor variables that make use of the entire history of a given output. This is different from other control charts that tend to treat each data point individually. With this strategy, each output (previous sample mean) is given a weighting defined by the user, and the most recent samples are weighted the highest. In addition, the EWMA chart is more sensitive for detecting smaller and moderate shifts in the process, in this case, in in-hospital mortality.

All analyses were conducted in R v.4.0.2 (R Foundation) ${ }^{12}$ and statistical significance was set at 0.05 .

\section{Results}

\section{Patients}

From 27 February to 22 October 2020, 466 patients with SARS-CoV-2 infection confirmed by PCR were recruited in 53 sites across six states and two territories in Australia. From these, five patients younger than 16 years were excluded, leaving 461 patients with confirmed COVID-19 for the final analysis. This number represented over $99 \%$ of all COVID-19 ICU admissions across Australia. ${ }^{11}$ Overall, 206 patients $(44.7 \%)$ were included in the first wave and $255(55.3 \%)$ in the second wave (Online Appendix, eFigure 1). The cumulative incidence of patients with COVID-19 and the number of ICU beds occupied per day by these patients are shown in Figure 1. The cumulative number of patients according to state is shown in the Online Appendix (eTable 1 and eFigure 2).

Baseline characteristics of the included patients are shown in Table 1 and Figure 2. Patients admitted in the second wave were younger, less often males, less often had chronic cardiac failure and were less frequently taking an angiotensin-converting enzyme inhibitor (ACEI) or an angiotensin II receptor blocker (ARB). Fever, cough, and sore throat were less frequent at presentation during the second wave, shortness of breath was more frequent (Figure 2). At baseline, patients admitted during the second wave had a higher heart and respiratory rate and lower temperature and oxygen saturation measured by pulse oximetry $\left(\mathrm{SpO}_{2}\right)$.
The only difference in laboratory findings at ICU admission was a lower lymphocyte count in the second wave (Online Appendix, eTable 2). Overall APACHE II illness severity scores were similar.

\section{Interventions and complications}

The interventions used and the development of complications in included patients are shown in Table 2 and Figure 2. While the use of remdesevir and steroids increased substantially in the second wave, the use of hydroxychloroquine decreased. The use of mechanical ventilation was similar between the periods, but in the second wave, the use of high flow nasal cannula, non-invasive ventilation and prone positioning was higher and the use of vasopressor, inotropic and neuromuscular blockage drugs was lower (Table 2 and Figure 2). During the second wave there was a lower incidence of viral pneumonitis.

\section{Clinical outcomes}

Hospital outcomes were available in all patients. Patients in the second wave had a shorter duration of ventilation and ICU and hospital length of stay compared with patients in the first wave (Table 3 and Figure 3). Crude ICU mortality in the second wave $(10.6 \%$ v $14.6 \%$; risk difference, -3.97 ; $95 \% \mathrm{Cl},-10.26$ to $2.07 ; P=0.203)$ and hospital mortality (12.2 v 14.6\%; risk difference, $-2.41 ; 95 \% \mathrm{Cl},-8.82$ to 3.80; $P=0.452$ ) were similar between the groups (Table 3 ). However, there was a greater likelihood of being discharged alive earlier at any time point during the second wave, even after adjustment for confounders (Figure 3). These findings were confirmed in analysis adjusted by APACHE ॥ and considering the centre of inclusion as random effect (Online Appendix, eTable 3).

Over time, hospital mortality constantly decreased and at the end of the second wave, it was lower than the risk of death predicted by APACHE II (Figure 4).

\section{Discussion}

\section{Key findings}

In this large multicentre study comparing the first and second waves of the disease, the outcomes for critically ill patients with COVID-19 admitted to ICUs in Australia have significantly improved. Specifically, the length of stay steadily decreased and patients were more likely to be discharged alive earlier in their ICU admission. Moreover, mortality was increasingly lower than predicted by illness severity scores. Coupled with this was evidence of practice change, with patients in the second wave more commonly receiving less invasive forms of respiratory support (including high flow oxygen and non- 


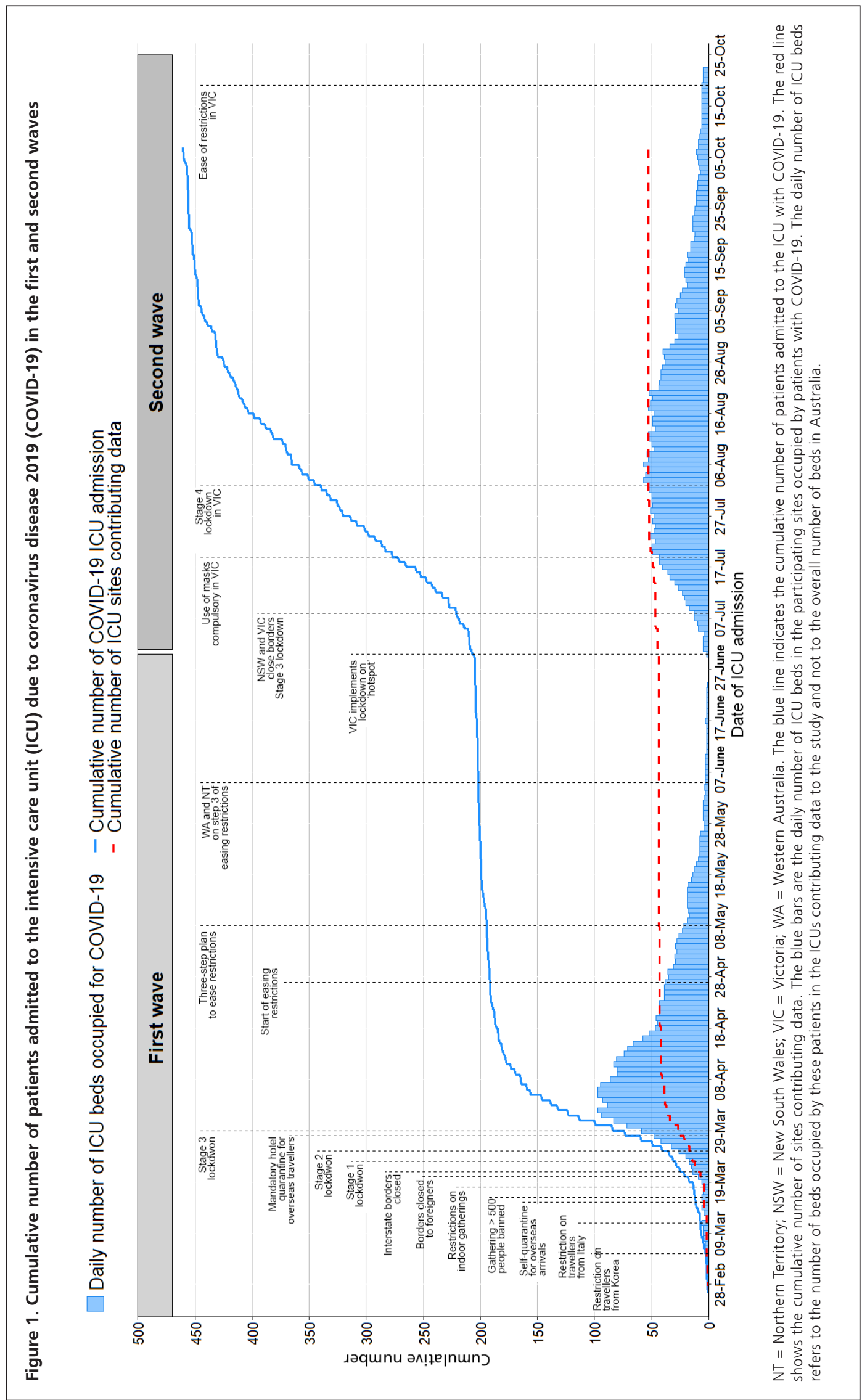

invasive ventilation), less vasopressor support, more proning and less neuromuscular blockade. There was a threefold increase in corticosteroid use and an almost 50\% increase in the use of remdesevir in the second wave, while the use of hydroxychloroquine fell. Although there were slight changes in the demographic characteristics between the first and second wave, with patients in the second wave being younger, with a less male predominance and less likely to be taking an ACEI or ARB or have chronic heart failure, they were more likely to be admitted to the ICU with greater physiological derangement. In this respect, overall APACHE \| scores did not differ significantly between the time periods.

Relationship to previous studies

Few studies have directly compared index and subsequent populations of critically ill patients with COVID-19. In an observational study of 2904 hospitalised patients with COVID-19 in Houston, Texas, there was a similar demographic shift towards younger patients with fewer comorbidities. ${ }^{13}$ Utilisation of mechanical ventilation and hospital length of stay were also 


\section{ORIGINAL ARTICLE}

Table 1. Baseline characteristics of the included patients at hospital admission

\begin{tabular}{|c|c|c|c|c|}
\hline & First wave & Second wave & $\begin{array}{l}\text { Absolute difference } \\
\qquad(95 \% \mathrm{Cl})^{*}\end{array}$ & $P$ \\
\hline Total number of patients & 206 & 255 & & \\
\hline Age (years), median (IQR) & $64.0(54.0-72.0)$ & $58.0(49.5-68.0)$ & $-5.18(-8.14$ to -2.23$)$ & 0.001 \\
\hline$<60$ & $78(37.9 \%)$ & $137(53.7 \%)$ & \multirow[t]{4}{*}{ 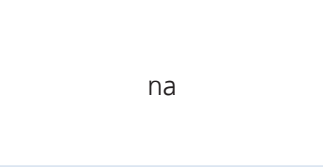 } & \multirow{4}{*}{$0.002^{+}$} \\
\hline $60-69$ & $56(27.2 \%)$ & $63(24.7 \%)$ & & \\
\hline $70-79$ & $62(30.1 \%)$ & $43(16.9 \%)$ & & \\
\hline$\geq 80$ & $10(4.9 \%)$ & $12(4.7 \%)$ & & \\
\hline Sex, male & $142(68.9 \%)$ & $153(60.0 \%)$ & $-8.93(-17.57$ to -0.14$)$ & 0.045 \\
\hline APACHE II score, median (IQR) & $14.0(10.0-18.0)$ & $14.0(10.0-18.0)$ & $-0.00(-1.36$ to 1.36$)$ & 0.998 \\
\hline \multicolumn{5}{|l|}{ Days with symptoms, median (IQR) } \\
\hline Hospital admission & $6.0(3.4-8.8)$ & $7.0(4.1-9.3)$ & $0.97(-0.12$ to 2.06$)$ & 0.080 \\
\hline ICU admission & $8.3(5.2-11.2)$ & $7.9(5.4-10.4)$ & $-0.25(-1.33$ to 0.84$)$ & 0.654 \\
\hline Median body mass index, $\mathrm{kg} / \mathrm{m}^{2}$ (IQR) & $28.8(24.5-32.3)$ & $30.5(26.8-35.7)$ & $1.80(-0.20$ to 3.79$)$ & 0.078 \\
\hline Underweight & 2/190 (1.1\%) & 0/209 (0.0\%) & \multirow{6}{*}{ na } & \multirow{6}{*}{$0.011^{\dagger}$} \\
\hline Normal weight & $54 / 190(28.4 \%)$ & $32 / 209(15.3 \%)$ & & \\
\hline Overweight & $52 / 190(27.4 \%)$ & $69 / 209(33.0 \%)$ & & \\
\hline Obesity, class I & $46 / 190(24.2 \%)$ & $51 / 209(24.4 \%)$ & & \\
\hline Obesity, class II & $22 / 190(11.6 \%)$ & $30 / 209(14.4 \%)$ & & \\
\hline Obesity, class III & $14 / 190(7.4 \%)$ & $27 / 209(12.9 \%)$ & & \\
\hline Health care worker & $17 / 196(8.7 \%)$ & $27 / 239(11.3 \%)$ & $2.62(-3.13$ to 8.27$)$ & 0.361 \\
\hline \multicolumn{5}{|l|}{$\begin{array}{l}\text { Number and type of co-existing } \\
\text { disorders }\end{array}$} \\
\hline 0 & $67(32.5 \%)$ & $79(31.0 \%)$ & \multirow{4}{*}{ na } & \multirow{4}{*}{$0.236^{+}$} \\
\hline 1 & $43(20.9 \%)$ & $74(29.0 \%)$ & & \\
\hline 2 & $46(22.3 \%)$ & $50(19.6 \%)$ & & \\
\hline$>2$ & $50(24.3 \%)$ & $52(20.4 \%)$ & & \\
\hline Diabetes & $57(27.7 \%)$ & $79 / 236(33.5 \%)$ & $5.80(-2.82$ to 14.32$)$ & 0.185 \\
\hline Obesity & $51(24.8 \%)$ & $68 / 235(28.9 \%)$ & $4.18(-4.14$ to 12.40$)$ & 0.322 \\
\hline Use of ACEI or ARB & $51 / 205(24.9 \%)$ & 40/236 (16.9\%) & $-7.93(-15.60$ to -0.35$)$ & 0.041 \\
\hline Chronic cardiac failure & 40 (19.4\%) & $26 / 236(11.0 \%)$ & $-8.40(-15.24$ to -1.74$)$ & 0.014 \\
\hline Smoker & $27(13.1 \%)$ & $28 / 234(12.0 \%)$ & $-1.14(-7.46$ to 5.06$)$ & 0.719 \\
\hline Chronic pulmonary disease $^{\ddagger}$ & $16(7.8 \%)$ & $17 / 236(7.2 \%)$ & $-0.56(-5.66$ to 4.38$)$ & 0.822 \\
\hline Asthma & $22(10.7 \%)$ & $38 / 236(16.1 \%)$ & $5.42(-0.95$ to 11.76$)$ & 0.092 \\
\hline Immunosuppression & $13(6.3 \%)$ & $20 / 236(8.5 \%)$ & $2.16(-2.81$ to 7.11$)$ & 0.383 \\
\hline Chronic kidney disease & $11(5.3 \%)$ & $17 / 236(7.2 \%)$ & $1.86(-2.77$ to 6.47$)$ & 0.418 \\
\hline Chronic haematological disease & $9(4.4 \%)$ & $5 / 236(2.1 \%)$ & $-2.25(-5.95$ to 1.04$)$ & 0.187 \\
\hline Cancer & $4(1.9 \%)$ & $12 / 236(5.1 \%)$ & $3.14(-0.27$ to 6.79$)$ & 0.068 \\
\hline \multicolumn{5}{|l|}{ Symptoms } \\
\hline Fever & 166/196 (84.7\%) & $172 / 236(72.9 \%)$ & $-11.81(-19.36$ to -4.14$)$ & 0.002 \\
\hline Cough & 153/196 (78.1\%) & $155 / 236(65.7 \%)$ & $-12.38(-20.68$ to -3.91$)$ & 0.004 \\
\hline Shortness of breath & 133/196 (67.9\%) & 185/236 (78.4\%) & $10.53(2.17-18.94)$ & 0.014 \\
\hline Fatigue & $117 / 196(59.7 \%)$ & $126 / 236(53.4 \%)$ & $-6.30(-15.60$ to 3.09$)$ & 0.187 \\
\hline Myalgia & 68/196 (34.7\%) & 70/235 (29.8\%) & $-4.91(-13.78$ to 3.93$)$ & 0.278 \\
\hline Diarrhoea & $65 / 195(33.3 \%)$ & $59 / 235(25.1 \%)$ & $-8.23(-16.87$ to 0.38$)$ & 0.062 \\
\hline Sore throat & $49 / 196(25.0 \%)$ & $37 / 236(15.7 \%)$ & $-9.32(-17.03$ to -1.74$)$ & 0.017 \\
\hline Anosmia & $25 / 195(12.8 \%)$ & $25 / 235(10.6 \%)$ & $-2.18(-8.47$ to 3.90$)$ & 0.485 \\
\hline Runny nose & $22 / 196(11.2 \%)$ & $25 / 236(10.6 \%)$ & $-0.63(-6.70$ to 5.26$)$ & 0.834 \\
\hline \multicolumn{5}{|l|}{$\begin{array}{l}\text { Signs at hospital admission, median } \\
\text { (IQR) }\end{array}$} \\
\hline Heart rate, beats/min & $95.0(84.8-110.0)$ & $103.0(92.0-114.0)$ & $7.74(3.39-12.10)$ & 0.001 \\
\hline Respiratory rate, breaths/min & $28.0(22.0-35.0)$ & $32.0(26.0-40.0)$ & $\begin{array}{r}4.02(1.86-6.17) \\
\text { (Contin }\end{array}$ & $\begin{array}{l}<0.001 \\
\text { es) }\end{array}$ \\
\hline
\end{tabular}


Table 1. Baseline characteristics of the included patients at hospital admission (continued)

\begin{tabular}{|c|c|c|c|c|}
\hline & First wave & Second wave & $\begin{array}{l}\text { Absolute difference } \\
(95 \% \mathrm{Cl})^{*}\end{array}$ & $P$ \\
\hline Mean arterial pressure, $\mathrm{mmHg}$ & $82.7(72.0-96.0)$ & $78.3(69.0-93.3)$ & $-4.30(-8.91$ to 0.32$)$ & 0.068 \\
\hline Temperature, ${ }^{\circ} \mathrm{C}$ & $38.4(37.8-39.0)$ & $38.0(37.2-38.8)$ & $-0.40(-0.66$ to -0.14$)$ & 0.003 \\
\hline $\mathrm{SpO}_{2^{\prime}} \%$ & $92.0 \%(89.0-95.0 \%)$ & $91.0 \%(86.0-94.0 \%)$ & $\begin{array}{c}-1.93 \%(-3.46 \% \text { to } \\
-0.41 \%)\end{array}$ & 0.013 \\
\hline
\end{tabular}

APACHE = Acute Physiology and Chronic Health Evaluation; ACEI = angiotensin-converting enzyme inhibitor; $A$ RB = angiotensin II receptor blocker; $\mathrm{ICU}=$ intensive care unit; IQR = interquartile range; na = not applicable. Percentages may not total 100 because of rounding. * Absolute difference is risk difference for categorical variables and median difference for continuous variables. First wave was used as reference (negative values represent decrease in second wave). $+P$ value estimated from Fisher exact test. $\neq$ Not considering asthma.

Figure 2. Coexisting disorders, symptoms, interventions and complications in patients admitted to the intensive care unit (ICU) due to coronavirus disease 2019 (COVID-19) in the first and second waves*
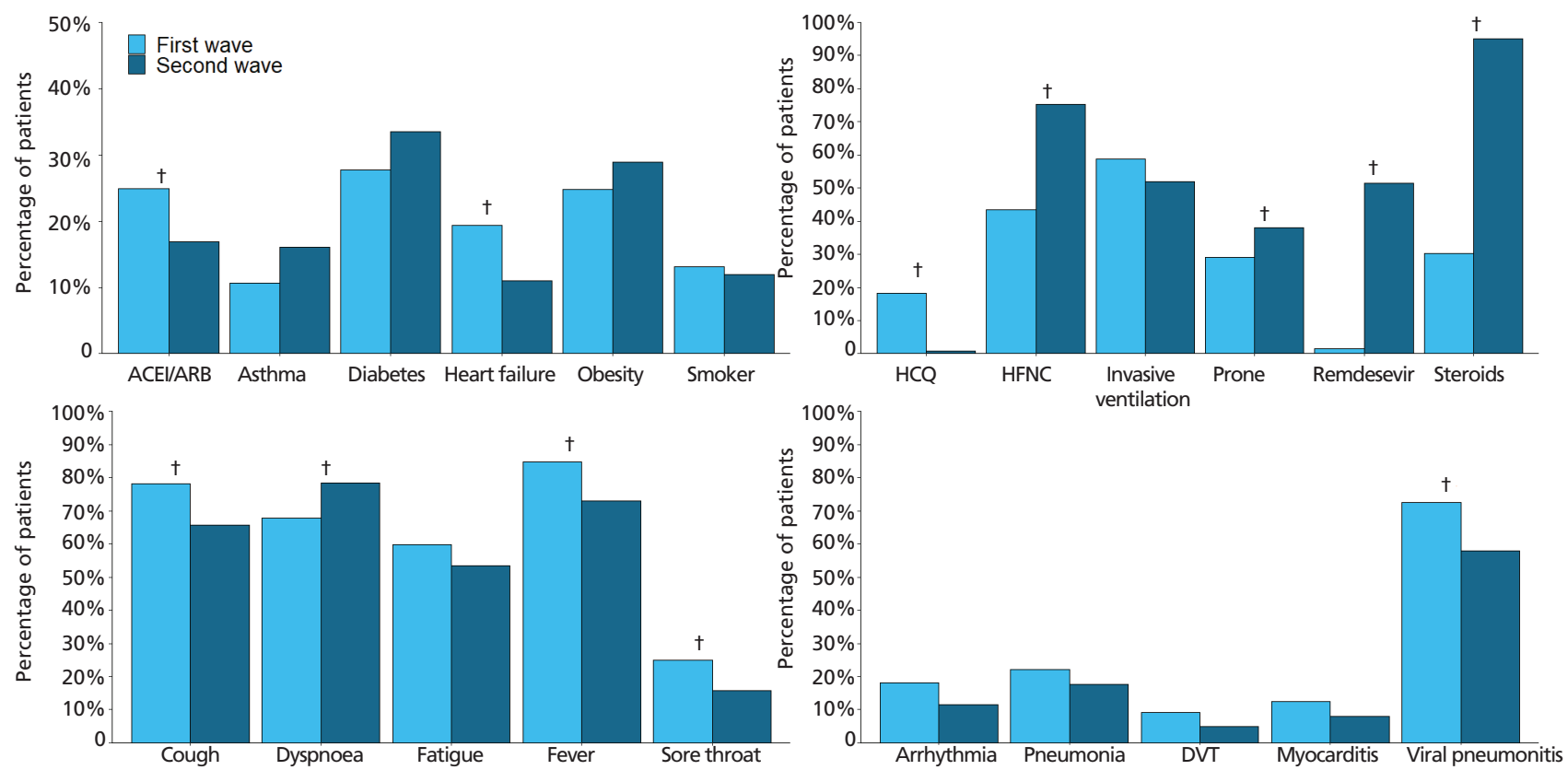

ACEI = angiotensin-converting enzyme inhibitor; $\mathrm{ARB}=$ angiotensin II receptor blocker; DVT = deep vein thrombosis; HCQ = hydroxychloroquine; HFNC = high flow nasal cannula. * Patients were categorised into "first wave" for ICU admissions occurring earlier than 1 July 2020 and into "second wave" for ICU admissions occurring from 1 July to 22 October 2020. $+P<0.05$ ( $P$ value available in the tables).

reduced. In another observational study of 21000 people admitted to critical care units in England between March and June 2020, mortality was demonstrated to decrease over time after adjusting for multiple factors. ${ }^{14}$ Several other studies and a systematic review have also noted this trend. ${ }^{15}$ Many of these studies were limited by a predominance of hospitalised and high dependency unit patients and lack of granular data about critical care interventions and treatments received. Furthermore, in comparison to countries with a much higher number of infections, the Australian health care system as a whole over this period was relatively well resourced and not under significant strain. However, given the second wave was more geographically isolated, with a much smaller number of hospitals managing these cases, it is likely resources, staff and equipment were affected locally. ${ }^{16}$

Data from this study illustrate that clinical management changed over the course of the COVID-19 pandemic. Several early guidelines suggested avoiding non-invasive ventilation and high flow oxygen due to concerns about aerosolisation of SARSCoV-2, and instead recommended earlier intubation. ${ }^{17}$ However, 
Table 2. Interventions and development of complications in the included patients

\begin{tabular}{|c|c|c|c|c|}
\hline & First wave & Second wave & $\begin{array}{c}\text { Absolute difference } \\
(95 \% \mathrm{Cl})^{*}\end{array}$ & $P$ \\
\hline Total number of patients & 206 & 255 & & \\
\hline \multicolumn{5}{|l|}{ Interventions } \\
\hline \multicolumn{5}{|l|}{ Drugs } \\
\hline - Antibiotics & $178 / 195(91.3 \%)$ & $214 / 235(91.1 \%)$ & $-0.22(-5.60$ to 5.34$)$ & 0.937 \\
\hline - Steroids & $59 / 195(30.3 \%)$ & $229 / 241(95.0 \%)$ & $64.76(57.48-71.46)$ & $<0.001$ \\
\hline - Hydroxychloroquine & $35 / 193(18.1 \%)$ & $2 / 238(0.8 \%)$ & $-17.29(-23.22$ to -12.11$)$ & $<0.001$ \\
\hline - Oseltamivir & $1 / 195(0.5 \%)$ & $0 / 238(0.0 \%)$ & na & $0.920^{+}$ \\
\hline - Lopinavir-ritonavir & $9 / 195(4.6 \%)$ & $4 / 238(1.7 \%)$ & $-2.93(-6.74$ to 0.29$)$ & 0.088 \\
\hline - Remdesevir & $3(1.5 \%)$ & $131(51.4 \%)$ & $49.92(43.52-56.20)$ & $<0.001$ \\
\hline \multicolumn{5}{|l|}{ Organ support ${ }^{\ddagger}$} \\
\hline - Mechanical ventilation & $121(58.7 \%)$ & $125 / 241(51.9 \%)$ & $-6.87(-16.02$ to 2.38$)$ & 0.144 \\
\hline - Inotropic or vasopressor & $113 / 196(57.7 \%)$ & $110 / 230(47.8 \%)$ & $-9.83(-19.20$ to -0.32$)$ & 0.042 \\
\hline - Neuromuscular blocking agent & $88 / 196(44.9 \%)$ & $80 / 232(34.5 \%)$ & $-10.42(-19.63$ to -1.13$)$ & 0.028 \\
\hline - High flow nasal cannula & $85 / 196(43.4 \%)$ & $176 / 234(75.2 \%)$ & $31.85(22.83-40.54)$ & $<0.001$ \\
\hline - Prone positioning & $57 / 196(29.1 \%)$ & $88 / 231(38.1 \%)$ & $9.01(0.03-17.85)$ & 0.048 \\
\hline - Renal replacement therapy & $25 / 196(12.8 \%)$ & $20 / 231(8.7 \%)$ & $-4.10(-10.20$ to 1.76$)$ & 0.174 \\
\hline - Non-invasive ventilation & $14 / 197(7.1 \%)$ & $38 / 230(16.5 \%)$ & $9.42(3.39-15.50)$ & 0.002 \\
\hline - Other cardiac procedures & $12 / 196(6.1 \%)$ & 10/232 (4.3\%) & $-1.81(-6.34$ to 2.42$)$ & 0.404 \\
\hline - Tracheostomy & $13 / 196(6.6 \%)$ & $20 / 231(8.7 \%)$ & $2.03(-3.14$ to 7.12$)$ & 0.430 \\
\hline - Inhaled nitric oxide & $13 / 196(6.6 \%)$ & $13 / 232(5.6 \%)$ & $-1.03(-5.83$ to 3.54$)$ & 0.659 \\
\hline - Extracorporeal membrane oxygenation & $2 / 196(1.0 \%)$ & $10 / 232(4.3 \%)$ & na & $0.078^{+}$ \\
\hline \multicolumn{5}{|l|}{ Development of complications } \\
\hline Viral pneumonitis & $140 / 193(72.5 \%)$ & $129 / 223(57.8 \%)$ & $-14.69(-23.62$ to -5.57$)$ & 0.001 \\
\hline Bacterial pneumonia & $42 / 190(22.1 \%)$ & $38 / 215(17.7 \%)$ & $-4.43(-12.30$ to 3.34$)$ & 0.265 \\
\hline Bacteraemia & $29 / 190(15.3 \%)$ & $21 / 225(9.3 \%)$ & $-5.93(-12.48$ to 0.37$)$ & 0.068 \\
\hline Stroke & $3 / 192(1.6 \%)$ & $0 / 226(0.0 \%)$ & na & $0.192^{+}$ \\
\hline Arrhythmia & $35 / 193(18.1 \%)$ & $26 / 227(11.5 \%)$ & $-6.68(-13.66$ to 0.09$)$ & 0.055 \\
\hline Barotrauma ${ }^{\S}$ & $12 / 193(6.2 \%)$ & $6 / 225(2.7 \%)$ & $-3.55(-7.93$ to 0.34$)$ & 0.082 \\
\hline Cardiac arrest & $4 / 192(2.1 \%)$ & $4 / 226(1.8 \%)$ & $-0.31(-3.33$ to 2.46$)$ & 0.817 \\
\hline Pulmonary embolism & $7 / 176(4.0 \%)$ & $11 / 224(4.9 \%)$ & $0.93(-3.37$ to 5.06$)$ & 0.651 \\
\hline Deep vein thrombosis & $16 / 176(9.1 \%)$ & $11 / 226(4.9 \%)$ & $-4.22(-9.65$ to 0.73$)$ & 0.104 \\
\hline Myocarditis & $22 / 176(12.5 \%)$ & $18 / 225(8.0 \%)$ & $-4.50(-10.79$ to 1.42$)$ & 0.144 \\
\hline
\end{tabular}

$\mathrm{ACEI}=$ angiotensin-converting enzyme inhibitor; $\mathrm{APACHE}=$ Acute Physiology and Chronic Health Evaluation; ARB = angiotensin II receptor blocker; $\mathrm{na}=$ not applicable. Percentages may not total 100 because of rounding. ${ }^{*}$ Absolute difference is risk difference. First wave was used as reference (negative values represent decrease in second wave). $\dagger P$ value estimated from Fisher exact test. $\ddagger$ Assessed daily until ICU discharge. $\S$ Defined as pneumothorax or pneumomediastinum or subcutaneous emphysema on chest x-ray or chest computed tomography scan.

as experience with COVID-19 in ICUs increased, ${ }^{18}$ Australian practice returned towards more routine and evidence-based management of patients with severe respiratory failure, with an emphasis on less invasive respiratory supports, while proning (a labour-intensive procedure requiring multiple people to enter the patient's room) also increased over time. These changes were also reflected in evolving Australian national guidelines. ${ }^{9}$
This study also illustrates the rapid translation of published trial data into Australian critical care practice between the first and second waves. Indeed, publication of the RECOVERY trial $^{7}$ resulted in a rapid and widespread threefold increase in corticosteroid use in Australian practice. Use of remdesivir, an antiviral drug, also significantly increased following the release of the ACTT II trial findings, ${ }^{8}$ although the recently completed 


\section{ORIGINAL ARTICLE}

Table 3. Clinical outcomes in the included patients

\begin{tabular}{|c|c|c|c|c|}
\hline & First wave & Second wave & $\begin{array}{c}\text { Absolute difference } \\
(95 \% \mathrm{Cl})^{*}\end{array}$ & $P$ \\
\hline Total number of patients & 206 & 255 & & \\
\hline $\begin{array}{l}\text { Duration of ventilation (days), median } \\
\text { (IQR) }\end{array}$ & $12.0(7.0-14.0)$ & $8.0(4.0-17.0)$ & $-3.05(-5.22$ to -0.89$)$ & 0.006 \\
\hline ICU length of stay (days), median (IQR) & $8.1(3.1-18.7)$ & $5.9(2.4-11.1)$ & \multirow{2}{*}{$1.35(1.10-1.64)^{\dagger}$} & \multirow{2}{*}{0.003} \\
\hline Truncated at extraction, days & $8.4(3.2-18.7)$ & $6.0(2.4-12.2)$ & & \\
\hline $\begin{array}{l}\text { Hospital length of stay (days), median } \\
\text { (IQR) }\end{array}$ & $17.3(8.9-30.5)$ & $14.2(8.6-21.1)$ & \multirow{2}{*}{$1.24(1.01-1.51)^{\dagger}$} & \multirow{2}{*}{0.037} \\
\hline Truncated at extraction, days & $17.6(9.0-32.4)$ & $14.7(8.9-23.0)$ & & \\
\hline ICU mortality & $30(14.6 \%)$ & $27(10.6 \%)$ & $-3.97(-10.26$ to 2.07$)$ & 0.203 \\
\hline Hospital mortality & $30(14.6 \%)$ & $31(12.2 \%)$ & $-2.41(-8.82$ to 3.80$)$ & 0.452 \\
\hline
\end{tabular}

$I C U$ = intensive care unit; IQR = interquartile range. Percentages may not total 100 because of rounding. * Absolute difference is risk difference for categorical variables and median difference for continuous variables. The first wave was used as reference (negative values represent decrease in second wave). + Subdistribution hazard ratio from a Fine-Gray competing risk model.

Figure 3. Cumulative incidence plot of intensive care unit (ICU) and hospital discharge according to the phase of the study*
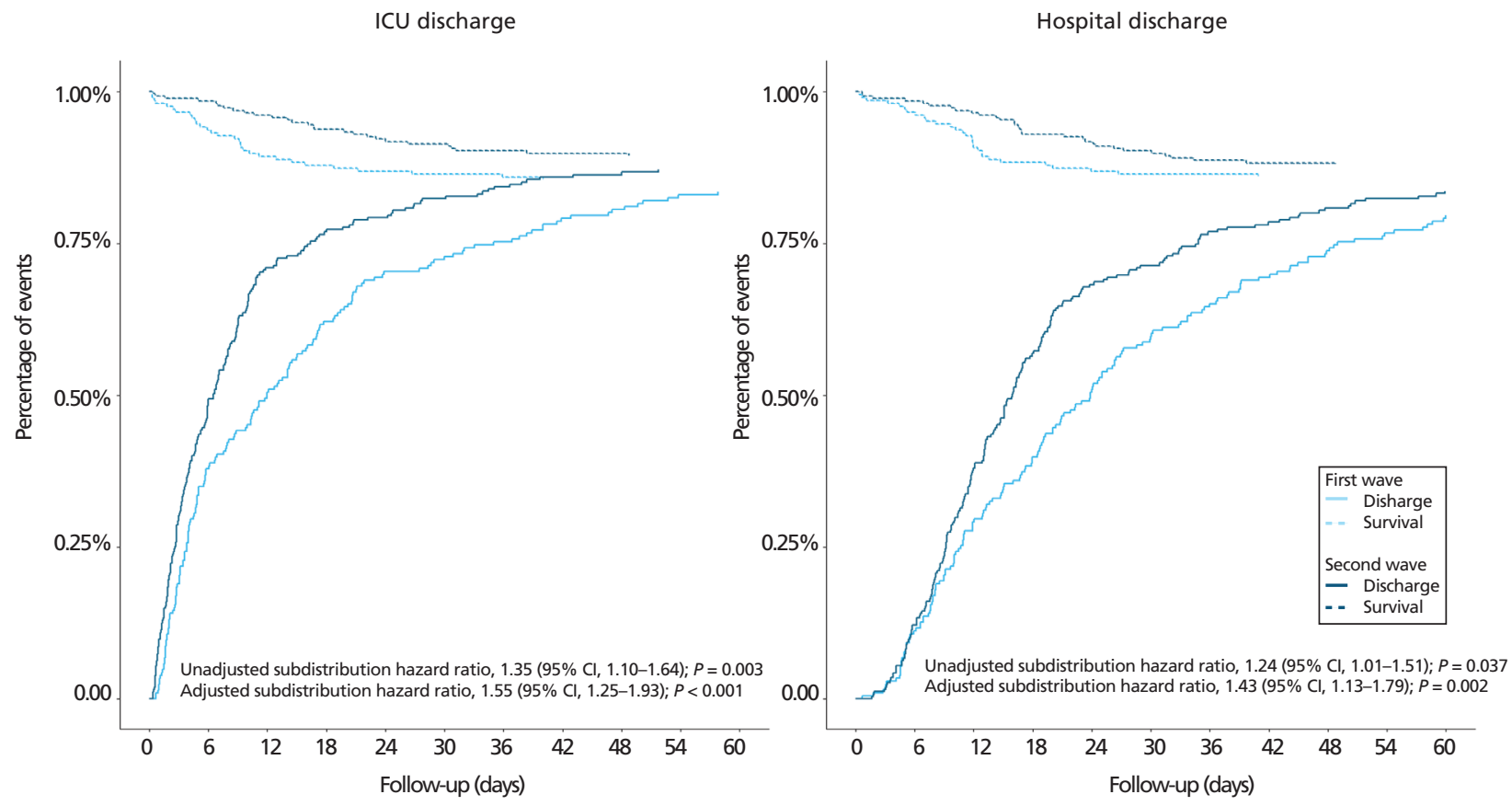

* Patients were categorised into "first wave" for ICU admissions occurring earlier than 1 July 2020 and into "second wave" for ICU admissions occurring from 1 July to 22 October 2020 .

larger WHO SOLIDARITY trial has raised further questions about its effectiveness. ${ }^{19}$ Finally, hydroxychloroquine, initially considered as a potential treatment for COVID-19, was not found to be effective and was potentially associated with increased death ${ }^{20}$ and its use rapidly declined.

\section{Study implications}

This study implies that the outcomes of critically ill patients with COVID-19 admitted to ICUs across Australia have improved over two distinct waves of the disease. Multiple 


\section{ORIGINAL ARTICLE}

\section{Figure 4. Exponentially weighted moving average (EWMA)*}

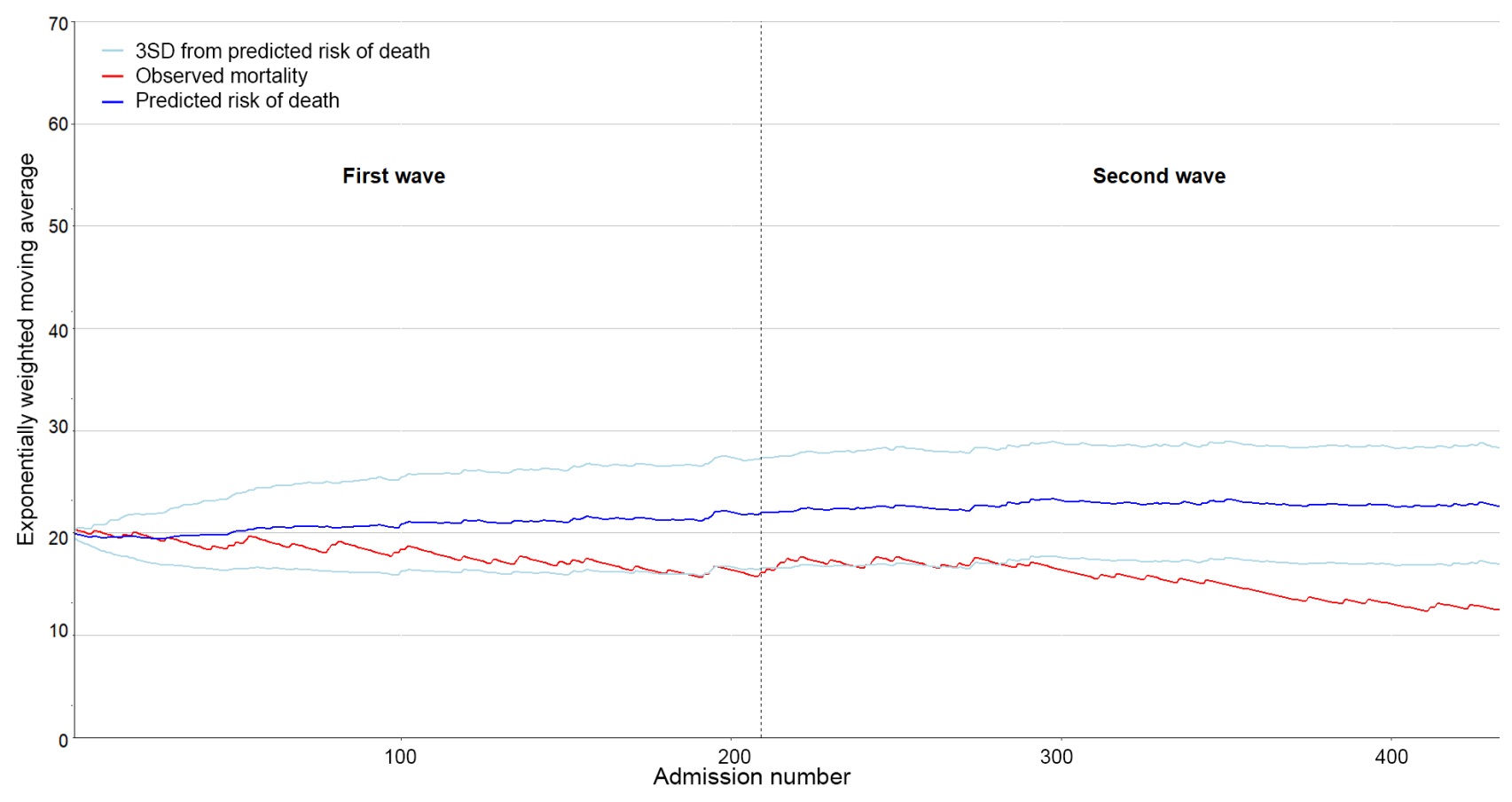

SD = standard deviation. * The EWMA was constructed considering a weight of 0.005, a target based on the initial predicted risk of death for each disease, and the boundaries of the predicted risk considered three standard deviations. The predicted risk of death was derived from Acute Physiology and Chronic Health Evaluation (APACHE) II score considering admission due to respiratory infection.

factors may be responsible, including changes in ICU practice that favoured less invasive forms of ventilation, the rapid uptake of new evidence-based treatments, the avoidance of non-evidence-based therapies, and possible changes in the demographic characteristics of patients that required ICU admission. Critically, this study has implications for other countries currently in the midst of or preparing for further COVID-19 outbreaks and reinforces the value of implementing and/or updating clinical practice guidelines with the latest evidence.

\section{Strengths and limitations}

This is the first study to provide detailed, national coverage of critically ill patients with COVID-19 over the course of both a complete first and second wave of cases. In both periods, over 99\% of the critically ill patients with COVID-19 in intensive care across Australia were included, with complete followup, and the same case report forms and data definitions were used, making the two cohorts highly comparable.

This study has several limitations. Only patients admitted to the ICU were included, and as such, our findings do not extend to the larger population of patients with COVID-19 admitted to hospital. Moreover, we have not collected detailed data concerning ICU admission practices, triage decisions or ICU occupancy and, therefore, we cannot exclude changes in admission criteria or ICU strain as potential sources of bias, but we note that the admission APACHE II scores were consistent across both periods. In addition, we did not collect data on virus virulence or host response, which may have affected clinical outcomes. Data from the first wave included all states and territories in Australia, while the second wave was almost exclusively from a single state. The data were censored, so some of the data for the second wave patients may not have been complete. Finally, for some therapeutic variables, such as corticosteroids, we did not collect any further data concerning type, dose, duration or indication, such that we are unable to undertake any more granular analysis.

\section{Conclusion}

During the second wave of COVID-19 in Australia, ICU and hospital length of stay of patients with COVID-19 admitted to the ICU decreased, and observed in-hospital mortality declined over time and was significantly lower 


\section{ORIGINAL ARTICLE}

than predicted by APACHE II scores. Multiple factors were associated with this, including changes in clinical management, the widespread and rapid adoption of evidenced-based practices, and changes in patient demographic characteristics but not illness severity.

Acknowledgements: SPRINT-SARI (Short Period Incidence Study of Severe Acute Respiratory Infection) Australia is supported by the Department of Health, Commonwealth of Australia (Standing Deed SON60002733).

The SPRINT-SARI Australia Management Committee: Aidan Burrell, Allen Cheng, Andrew Udy, Annamaria Palermo, Benjamin Reddi, Claire Reynolds, Craig French, D James Cooper, Edward Litton, Husna Begum, Lewis Campbell, Mahesh Ramanan, Mark Plummer, Richard McAllister, Simon Erickson, Tessa Broadley, Tony Trapani and Winston Cheung.

The SPRINT-SARI Australia Investigators: Adam Visser, Adrian Mattke, Adrian Regli, Alan Rashid, Alexis Tabah, Alison Walker, Allen Cheng, Amanda Corley, Andrew Udy, Anil Ramnani, (Isabel) Anne Leditschke, Anthony Eidan, Bart DeKeulenaer, Baumik Mevavala, Ben Mulholland, Benjamin Reddi, Brent Richards, Cameron Knott, Cara Moore, Carmel Delzoppo, Catherine Boschert, Catherine Tacon, Claire Corrigan, Craig French, Danielle Austin, David Brewster, David Cooper, David Crosbie, David Hawkins, Edda Jessen, Eduardo Martinez, Edward Fysh, Edward Litton, Felix Oberender, Forbes McGain, Gavin Salt, Glenn Eastwood, Gopal Taori, Hannah Thompson, Hayden White, Hergen Buscher, Ian Seppelt, Ifrah Khan, Janelle Young, Jayshree Lavana, Jeremy Cohen, Jessica Lugsdin, Jill Garlick, Jim Buttery, John Botha, John Santamaria, Jonathan Barrett, Kasha Singh, Kevin Laupland, Khaled El-Khawas, Kristine Estensen, Kush Deshpande, Kyle White, Leigh Fitzpatrick, Lewis Campbell, Mahesh Ramanan, Manoj Saxena, Marie Draper, Marion Kainer, Mark Kol, Mark Page, Mark Plummer, Martin Sterba, Matthew Anstey, Matthew Brain, Matthew Maiden, Myrene Kilminster, Naomi Hammond, Neeraj Bhadange, Nicole Humphreys, Paras Jain, Paul Azzi, Paul Secombe, Paula Lister, Peter Chan, Peter McCanny, Phillip Britton, Pierre Janin, Rashmi Runiyar, Ravi Krishnamurthy, Ravikiran Sonawane, Ravindranath Tiruvoipati, Rebecca Jessup, Richard Totaro, Rinaldo Bellomo, Ritesh Sanghavi, Samantha Bates, Sandra Peake, Shailesh Bihari, Shane George, Sharon Waterson, Simon Erickson, Steve Webb, Subhash Arora, Subodh Ganu, Thomas Rozen, Toni McKenna, Umesh Kadam, Vineet Nayyar, Wei Han Choy and Wisam Albassam.

The SPRINT-SARI Australia participating sites: Albury Wodonga Health (Leigh Fitzpatrick, Sarah White), Alice Springs Hospital (Paul Secombe, Shan Cairnes, Elizabeth Matthews), Angliss Hospital (Peter Chan, Stephanie Hunter), Austin Hospital (Rinaldo Bellomo, Glenn Eastwood, Leah Peck, Helen Young), Ballarat Base Hospital (Khaled El-Khawas, Dianne Hill), Bankstown-Lidcombe Hospital (Manoj Saxena, Magda Luciuk, Luke Lau, Kathleen Brennan, Diane Redmond, Magdalena Mannah), Barwon Health (Matthew Maiden, Michelle Horton, Allison Bone, Tania Salerno), Bendigo Hospital (Cameron Knott, Catherine Boschert, Julie Smith), Box Hill Hospital (Peter Chan, Stephanie Hunter), Bunbury Hospital (Ravi Krishnamurthy, Marie Draper), Bundaberg Hospital (Anthony Eidan, Angela Ratsch), Caboolture Hospital (Mahesh Ramanan, Julia Afleck, Kelsey Pateman, Ramsy D'souza), Cabrini Hospital Malvern (David Brewster, Shannon Simpson), Cairns Hospital (Catherine Tacon), Calvary Mater Newcastle (Alan Rashid, Toni McKenna, Jessica Lugsdin, Paras Jain), Campbelltown Hospital (Ritesh Sanghavi, Alyson France, Roland Eckhardt, Jodie Nema), Canberra
Hospital (Anil Ramnani, Mary Nourse), Concord Hospital (Mark Kol, Helen Wong), Casey Hospital (Gopal Taori, Amanda Hulley, Joanne Lillie, John Dong Young Lee), Dandenong Hospital (Gopal Taori, Subhash Arora, Ifrah Khan, Amanda Hulley, Joanne Lillie), Epworth Richmond (Jonathan Barrett, Gabrielle Hanlon), Fiona Stanley Hospital (Edward Litton, Annamaria Palermo), Flinders Medical Centre (Shailesh Bihari, Tapaswi Shrestha), Frankston Hospital (John Botha, Kasha Singh, Ravindranath Tiruvoipati, Jodie Prendergast), Gold Coast University Hospital (Brent Richards, Shane George, Mandy Tallott, Priscilla Harvey), Hervey Bay Hospital (Wei Han Choy, Angela Ratsch), Ipswich Hospital (Neeraj Bhadange, Steven Tyler), John Hunter Hospital (Eduardo Martinez, Dustin Bush, Federica Cazzola, Gail Brinkerhoff, Krishna Sunkara), Joondalup Health Campus (David Hawkins, Ben Mulholland), Launceston General Hospital (Matthew Brain, Sarah Mineall), Lismore Base Hospital (Myrene Kilminster), Liverpool Hospital (Peter McCanny, Danielle Austin, Alyson France, Diane Redmond, Kelsey Dobell-Brown, Win Hlaing), Logan Hospital (Hayden White, Kristine Estensen, Lynette Morrison, Joanne Sutton, Melanie Cooper, Rebecca Stokman), Lyell McEwan Hospital (Edda Jessen, Natalie Soar), Maroondah Hospital (Peter Chan, Stephanie Hunter), Mater Hospital Brisbane (Isabel Anne Leditshke, Katherine Jongebloed), Mildura Base Hospital (Alison Walker, Andrea Bock), Monash Children's Hospital (Felix Oberender, Jess Waghorn, Jim Buttery), Monash Medical Centre (Wisam Albassam, Amanda Hulley, Joanne Lillie, Lucy Soden), Nepean Hospital (Ian Seppelt, Christina Whitehead, Kirsty Masters), Northeast Health Wangaratta (Nicole Humphreys, Rowan O'Hagan), Northern Hospital (David Crosbie, Rebecca Jessup, Simone Said), Perth Children's Hospital (Simon Erickson, Hannah Thomson), Port Macquarie Base Hospital (Paul Azzi), Prince of Wales Hospital (Gavin Salt, Solomon Thambiraj), Princess Alexandra Hospital (Kyle White, Jason Meyer, Meg Harward), Queensland Children's Hospital (Adrian Mattke, Kerry Johnson), Redcliffe Hospital (Alexis Tabah, Maree Duroux, Megan Ratcliffe), Rockingham Hospital (Ravikiran Sonawane), Royal Adelaide Hospital (Benjamin Reddi, Stephanie O'Connor) Royal Brisbane and Women's Hospital (Jeremy Cohen, Kevin Laupland, Melissa Lassig Smith, Cheryl Fourie, Janine Stuart), Royal Children's Hospital (Thomas Rozen, Carmel Delzoppo, Alyssa Serratore), Royal Darwin Hospital (Lewis Campbell, Martin Hansen, Kirsty Smith, Rebecca Garcia), Royal Hobart Hospital (David Cooper, Richard McAllister), Royal Melbourne Hospital (Mark Plummer, Cara Moore, Amy Laird, David Priddle, Emily Alexander, Louise Rait, Monica Rundle), Royal North Shore Hospital (Naomi Hammond, Pierre Janin, Angela Ashelford, Elizabeth Yarad, Frances Bass), Royal Perth Hospital (Steve Webb, Sharon Waterson), Royal Prince Alfred Hospital (Richard Totaro, Heidi Buhr, Jennifer Coles), Sir Charles Gairdner Hospital (Matthew Anstey, Erina Myers, Rashmi Runiyar), St George Hospital (Kush Deshpande, Deborah Inskip, Jennene Miller), St John of God Hospital Midland (Edward Fysh, Bhaumik Mevavala), St John of God Hospital Murdoch (Adrian Regli, Bart DeKeulenaer, Annamaria Palermo), St Vincent's Hospital Melbourne (John Santamaria, Jennifer Holmes), St. Vincent's Hospital Sydney (Hergen Buscher, Claire Reynolds), Sunshine Coast University Hospital (Paul Lister, Jane Brailsford, Lauren Murray, Loretta Forbes, Teena Maguire), Sydney Children's Hospital Randwick (Janelle Young), the Alfred Hospital (Allen Cheng, Andrew Udy, Jill Garlick, Meredith Young, Emma Martin, Jasmine Board, Phoebe McCracken), the Children's Hospital at Westmead (Phillip Britton, Jonathan Egan, Gail Harper), the Prince Charles Hospital (Jayshree Lavana, Amanda Corley, India Lye, Lacey Irvine, Niki McGuinness), the Queen Elizabeth Hospital (Sandra Peake, Patricia Williams), Toowoomba Hospital (Adam Visser, 


\section{ORIGINAL ARTICLE}

Judy Smith), Warrnambool Base Hospital (Mark Page, Tina Johnstone), Werribee Mercy Hospital (Umesh Kadam, Marlene Gojanovic), Western Health: Footscray (Craig French, Forbes McGain, Marion Kainer, Samantha Bates, Miriam Towns, Rebecca McEldrew, Rebecca Morgan), Western Health: Sunshine (Craig French, Forbes McGain, Marion Kainer, Samantha Bates, Miriam Towns, Rebecca McEldrew, Rebecca Morgan), Westmead Hospital (Vineet Nayyar, Jing Kong), Wollongong Hospital (Martin Sterba, Wenli Geng) and Women's and Children's Hospital Adelaide (Subodh Ganu, Georgia Letton).

\section{Competing interests}

No relevant disclosures.

\section{Author details}

Aidan JC Burrell1,

Ary Serpa Neto ${ }^{1}$

Tessa Broadley ${ }^{1}$

Tony Trapani ${ }^{1}$

Husna Begum ${ }^{1}$

Lewis T Campbell3,4

Allen C Cheng ${ }^{5,6}$

Winston Cheung ${ }^{7}$

D James Cooper ${ }^{1,2}$

Simon J Erickson ${ }^{8}$

Craig J French ${ }^{1,9}$

John M Kaldor ${ }^{10}$

Edward Litton ${ }^{11,12}$

Srinivas Murthy ${ }^{13}$

Richard E McAllister ${ }^{14}$

Alistair D Nichol ${ }^{1,2}$

Annamaria Palermo ${ }^{11}$

Mark P Plummer ${ }^{15}$

Mahesh Ramanan ${ }^{16}$

Benjamin AJ Reddi17,18

Claire Reynolds ${ }^{19}$

Steve A Webb ${ }^{1,12}$

Andrew A Udy 1,2

For the SPRINT SARI Australia Investigators*

* The list of SPRINT-SARI Australia Investigators is also available in the Online Appendix.

1 Australian and New Zealand Intensive Care Research Centre (ANZIC-RC), School of Public Health and Preventive Medicine, Monash University, Melbourne, VIC, Australia.

2 Department of Intensive Care and Hyperbaric Medicine, The Alfred Hospital, Melbourne, VIC, Australia.

3 Intensive Care Unit, Royal Darwin Hospital, Darwin, NT, Australia.

4 Menzies School of Health Research, Darwin, NT, Australia.

5 School of Public Health and Preventive Medicine, Monash University, Melbourne, VIC, Australia.

6 Infection Prevention and Healthcare Epidemiology Unit, Alfred
Health, Melbourne, VIC, Australia.

7 Department of Intensive Care Medicine, Concord Repatriation General Hospital, Sydney, NSW, Australia.

8 Perth Children's Hospital, Perth, WA, Australia.

9 Department of Intensive Care, Western Health, Melbourne, VIC, Australia.

10 The Kirby Institute, University of New South Wales, Sydney, NSW, Australia.

11 Intensive Care Unit, Fiona Stanley Hospital, Perth, WA, Australia.

12 Department of Intensive Care Medicine, St John of God Hospital Subiaco, Perth, WA, Australia.

13 Faculty of Medicine, University of British Columbia, Vancouver, Canada.

14 Department of Critical Care Medicine, Royal Hobart Hospital, Hobart, TAS, Australia.

15 Intensive Care Unit, Royal Melbourne Hospital, Melbourne, VIC, Australia.

16 Intensive Care Unit, Caboolture Hospital, Caboolture, QLD, Australia.

17 Royal Adelaide Hospital, Adelaide, SA, Australia.

18 University of Adelaide, Adelaide, SA, Australia.

19 Intensive Care Unit, St Vincent's Health Network, Sydney, NSW, Australia.

Correspondence: aidan.burrell@monash.edu

doi: https://doi.org/10.51893/2021.3.0A8

\section{References}

1 Lu H, Stratton CW, Tang YW,. Outbreak of pneumonia of unknown etiology in Wuhan, China: the mystery and the miracle. J Med Virol 2020; 92: 401-2.

2 Hui DS, Azhar El, Madani TA, et al. The continuing 2019-nCoV epidemic threat of novel coronaviruses to global health - The latest 2019 novel coronavirus outbreak in Wuhan, China. Int J Infect Dis 2020; 91: 264-6.

3 Chen N, Zhou M, Dong X, et al. Epidemiological and clinical characteristics of 99 cases of 2019 novel coronavirus pneumonia in Wuhan, China: a descriptive study. Lancet 2020; 395: 507-13.

4 World Health Organization. Weekly epidemiological update 24 November 2020. https://www.who.int/publications/m/item/ weekly-epidemiological-update---24-november-2020 (viewed Nov 2020).

5 Runciman WB, Hunt TD, Hannaford NA, et al. CareTrack: assessing the appropriateness of health care delivery in Australia. Med J Aust 2012; 197: 100-5.

6 Curtis K, Fry M, Shaban RZ, Considine J. Translating research findings to clinical nursing practice. J Clin Nurs 2017; 26: 862-72.

7 RECOVERY Collaborative Group; Horby P, Lim WS, et al. Dexamethasone in hospitalized patients with COVID-19. N Engl J Med 2021; 384: 693-704. 


\section{ORIGINAL ARTICLE}

8 Beigel JH, Tomashek KM, Dodd LE, et al; ACTT-1 Study Group Members. Remdesivir for the treatment of COVID-19 - final report. N Engl J Med 2020; 383: 1813-26.

9 National COVID-19 Clinical Evidence Taskforce. Caring for people with COVID-19: living guidelines. https:// covid19evidence.net.au/ (viewed Jan 2021).

10 Burrell AJC, Pellegrini B, Salimi F, et al. Outcomes of COVID-19 patients admitted to Australian intensive care units during the early phase of the pandemic. Med J Aust 2021; 214: 23-30.

11 COVID-19 National Incident Room Surveillance Team. COVID-19 Australia: epidemiology report 28: fortnightly reporting period ending 25 October 2020. Commun Dis Intell (2018) 2020; 44; doi: 10.33321/cdi.2020.44.84.

12 Team RC. R: A language and environment for statistical computing. Vienna, Austria: R Foundation for Statistical Computing, 2019.

13 Vahidy FS, Drews AL, Masud FN, et al. Characteristics and outcomes of COVID-19 patients during initial peak and resurgence in the Houston metropolitan area. JAMA 2020; 324: 998-1000.

14 Dennis JM, McGovern AP, Vollmer SJ, Mateen BA. Improving survival of critical care patients with coronavirus disease 2019 in England: a national cohort study, March to June 2020. Crit Care Med 2021; 49: 209-14.

15 Armstrong RA, Kane AD, Cook TM. Outcomes from intensive care in patients with COVID-19: a systematic review and metaanalysis of observational studies. Anaesthesia 2020; 75: 1340-9.

16 Pilcher D, Coatsworth NR, Rosenow M, McClure J. A national system for monitoring intensive care unit demand and capacity: the Critical Health Resources Information System (CHRIS). Med $J$ Aust 2021; 214: 297-8.

17 Phua J, Weng L, Ling L, et al; Asian Critical Care Clinical Trials Group. Intensive care management of coronavirus disease 2019 (COVID-19): challenges and recommendations. Lancet Respir Med 2021; 8: 506-17.

18 Ledford $\mathrm{H}$. Why do COVID death rates seem to be falling? Nature 2020; 587: 190-2.

19 WHO Solidarity Trial Consortium; Pan H, Peto R, HenaoRestrepo AM, et al. Repurposed antiviral drugs for COVID-19interim WHO SOLIDARITY trial results. N Engl J Med 2021; 384: 497-511.

20 RECOVERY Collaborative Group; Horby P, Mafham M, Linsell L, et al. Effect of hydroxychloroquine in hospitalized patients with COVID-19. N Engl J Med 2020; 383: 2030-40. 